\title{
Critical Care Problem in a Case of Intracerebral Hemorrhage Due to Eclampsia and Its Ethics and Medicolegal Consideration
}

\author{
Kulsum Kulsum ${ }^{1,2} \mathbb{D}$, Taufik Suryadi ${ }^{3,4 *}$ (D) \\ ${ }^{1}$ Department of Anesthesiology and Intensive Therapy, Medical Faculty, Universitas Syiah Kuala, The Zainoel Abidin Hospital, \\ Banda Aceh, Indonesia; ${ }^{2}$ Neuro-anesthesia and Critical Care Consultant, Medical Faculty, Universitas Syiah Kuala, The Zainoel \\ Abidin Hospital, Banda Aceh, Indonesia; ${ }^{3}$ Department of Forensic Medicine and Medicolegal, Medical Faculty, Universitas Syiah \\ Kuala, The Zainoel Abidin Hospital, Banda Aceh, Indonesia; ${ }^{4}$ Ethics and Medicolegal Consultant, Medical Faculty, Universitas \\ Syiah Kuala, The Zainoel Abidin Hospital, Banda Aceh, Indonesia
}

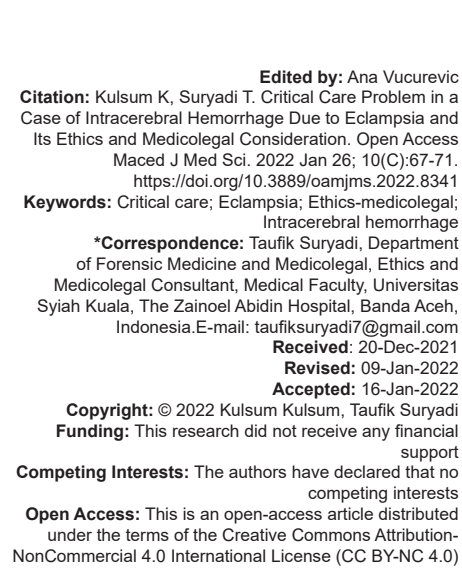

\section{Introduction}

Mortality and morbidity rates in pregnant women with complications of pre-eclampsia and eclampsia are still quite high in developing country which is around $5-10 \%$, while fetal mortality is around $40 \%$ [1]. The causes of maternal death with pre-eclampsia and eclampsia occur as a result of complications from heart failure, kidney failure, pulmonary edema, and brain hemorrhage [1], [2]. Pre-eclampsia is an accumulation of polymorphic clinical symptoms (syndromes) that can involve all organs, whereas eclampsia is a continuation of pre-eclampsia accompanied by seizures without any other cause [1]. Etiology of pre-eclampsia is not specifically known in pregnant women. This syndrome is characterized by symptoms of hypertension, edema, and proteinuria that occur after the $20^{\text {th }}$ weeks of pregnancy until the $1^{\text {st }}$ week after delivery [2].
The incidence of pre-eclampsia and eclampsia from all pregnancies ranges from 5 to $10 \%$ which occurs as a result of several risks in pregnancy such as maternal age ( $<16$ years or more than 45 years), the presence of hypertension before pregnancy, first pregnancy, molar pregnancy, twins baby, and obesity, as well as a history of pre-eclampsia in a previous pregnancy. Among these risk factors, it is difficult to determine which risk factors are the main causes of pre-eclampsia and eclampsia [3]. The severity of pre-eclampsia is characterized by blood pressure above 160/110 $\mathrm{mmHg}$, visual disturbances, pulmonary edema, upper abdominal pain, fetal growth is stunted, and from laboratory tests hemolysis, thrombocytopenia, proteinuria $2+$, and oliguria. If these symptoms are accompanied by seizures, they are called eclampsia [4].

The predominant clinical manifestations in pre-eclampsia are proteinuria and hypertension and frequent complications are kidney failure, damage to 
the liver, and intracranial hemorrhage [5]. The maternal and fetal death rates increase if the patient experiences seizures due to circulatory collapse [2]. Besides the kidney and brain, liver involvement in pre-eclampsia and eclampsia is a serious matter along with hemolysis and thrombocytopenia into a syndrome called hemolysis elevated liver enzymes low platelet (HELLP) [4].

In eclampsia, non-lethal intracerebral hemorrhages $(\mathrm{ICH})$ often occur, but in some cases, sudden death occurs after a seizure and is the result of massive cerebral hemorrhage. In pregnant women with a history of chronic hypertension, bleeding is more likely to occur as a secondary result of lypohyalinosis that damages small- and medium-sized cerebral arteries in the brainstem, cerebellum, striato-capsular, and thalamus areas. Bleeding like this often occurs in young mothers with eclampsia accompanied by HELLP syndrome and eclampsia [6].

\section{Case Report}

In this article, we report a case of a 23-yearold pregnant woman, gravida 2 (G2), 1-time delivery (D1), an abortion that has never been (A0) symbolized by $\mathrm{G} 2 \mathrm{D} 1 \mathrm{~A} 0$, the patient has eclampsia accompanied by HELLP syndrome and $\mathrm{ICH}$. The patient came to the emergency department for a referral from rural hospital, after a cesarean section (CS) was performed for eclampsia indications. At the time of admission to the emergency room of Zainoel Abidin hospital, the patient had decreased consciousness with the Glasgow coma scale (GCS) Eye-1, Motoric-1, Verbal-1 (E1M1V1), installed endotracheal intubation, and experienced seizures 73 times. Medical history is hypertension and diabetes mellitus. The obstetric history of the patient performing routine antenatal care (ANC) at the midwife but the patient was unaware of having experienced pre-eclampsia.

On physical examination while in the emergency room, the patient was unconscious with the GCS 3, blood pressure $75 / 42 \mathrm{mmHg}$, respiratory rate with a ventilator, circulation with pulses 63 beat $/ \mathrm{min}$, and pupil $6 \mathrm{~mm} / 6 \mathrm{~mm}$. Neurological status: Direct and indirect light reflexes were not found, cervical stiffness was found, and sensory function cannot be assessed. Laboratory tests found hemoglobin $7.8 \mathrm{~g} / \mathrm{dl}$, hematocrit $23 \%$, leukocytes $11,100 / \mathrm{mm}^{3}$, platelets $85,000 / \mathrm{mm}^{3}$, blood sugar $132 \mathrm{mg} / \mathrm{dl}$, sodium $145 \mathrm{mEq} / \mathrm{L}$, potassium $2.7 \mathrm{mEq} / \mathrm{L}, \mathrm{Cl} 115 \mathrm{mEq} / \mathrm{L}$, SGOT $178 \mathrm{U} / \mathrm{L}$, SGPT 102 $\mathrm{U} / \mathrm{L}$, and albumin $2.0 \mathrm{~g} / \mathrm{dl}$. From the head computed tomography (CT) scan, results obtained subarachnoid hemorrhage (SAH) filled the subarachnoid space, cisterna system, right parietal lobe sulci, and $\mathrm{ICH}$ in the right and left parietal and occipital lobes with a volume of approximately $120 \mathrm{cc}$ and cerebral edema.
The patient is then treated in the intensive care unit (ICU) and a head CT scan is performed with extensive $\mathrm{ICH}$. While in the $\mathrm{ICU}$, the patient was consulted to the neurosurgery department for emergency craniotomy for evacuation of $\mathrm{ICH}$. In the pre-anesthesia examination, the patient's condition was at the American Society of Anesthesiologists Level 5 , the patient obtained airway clear, breathing with respiratory rate with a ventilator, circulation with blood pressure $130 / 88 \mathrm{mmHg}$, pulse 48 times/min, and pupil $6 \mathrm{~mm} / 6 \mathrm{~mm}$, the patient experienced an increase acute intracranial pressure, GCS 3 (E1M1V1), and seizures was found. The results of the neuroanesthesia and neurosurgery team's assessment stated that there was no indication of surgery in the patient because there had been extensive bleeding accompanied by brain edema, so treatment was recommended only conservatively. The patient then underwent treatment in the ICU to improve the critical condition of the patient but after 4 days being treated in the ICU; the patient's condition did not improve even tended to decrease even though the treatment was optimal.

The ethical dilemmas faced by neuroanesthesia and critical care (NACC) consultants are: Will it continue to treat patients in the ICU even though the results will be in vain (futile treatment) or to limit intensive therapy because they concluded that the condition of the patient has a terminal stage?. In an effort to overcome this problem, in accordance with fixed procedures at the hospital, the NACC consultant consulted with an ethics and medicolegal consultant as a representation of the medical committee and ethical committee to determine the limitation or termination of life support for patients. This case report discusses how ethical and medicolegal decision-making for limiting or terminating life support in the case of terminal patients.

\section{Discussion}

\section{Patient's condition}

The ethical dilemma regarding critical care is still often a debate in the medical community. In critical care, which is often an ethical issue, is the limitation and termination of life support or what is often called withholding and withdrawing life support. Some medical practitioner still does not fully understand the problem of withholding and withdrawing life support so it needs a thorough discussion regarding its medical, ethical, and medicolegal aspects [7]. Medical practitioner must remain aware that in carrying out their profession not only is responsible for the health of patients (professional responsibility), but also responsible in the field of law (medico-legal responsibility), for services rendered [8]. 
The patient's condition while being treated in the ICU, the patient was unconscious with the depend of a ventilator and sophisticated medical equipment. The patient's condition was unstable and even tended to decline after being treated in the ICU for 4 days. The therapy provided is optimal but the patient is no longer responsive to the treatment. The doctors whom in charge of the patient (DCP) have stated that the treatment of patients has been in vain (futile treatment) because the patient's condition is terminal. The diagnosis of the patient when consulted by the medical committee is post CS for indications of eclampsia accompanied by HELLP syndrome and extensive $\mathrm{ICH}$.

The patients with G2D1A0 pregnancy should have regular ANC. Unfortunately, this patient found an obstetric history that was not supportive because the patient was not aware of having experienced preeclampsia. ANC aims to monitor the development of maternal and fetal pregnancy and can also immediately recognize the complications of pregnancy and childbirth and can immediately deal with complaints and diseases of pregnant women. This patient has eclampsia with HELLP syndrome. The results of a study conducted by Muhani and Besral [9], showed that the presence of eclampsia and HELLP syndrome as complications of severe pre-eclampsia became a predictor of the risk of maternal death 12 times higher than those without HELLP syndrome. The condition of the mother and fetus is progressively worsening and takes place suddenly due to the presence of HELLP syndrome [9]

The extensive cerebrovascular bleeding that occurs in these patients as well as hypertensive seizures and encephalopathy can be caused by hypertension in pre-eclampsia [10]. Other complications of hypertension include abruption of the placenta and heart failure [4], [10]. The response to acute severe hypertension in the brain results in a sudden increase in systemic blood pressure and impaired regulation of the cerebrovascular system leading to vasospasm, cytotoxic edema, ischemia, and infarction. SAH also occurs in pre-eclampsia. In some cases, little blood was found in the frontal or parietal lobes but only a few reported $\mathrm{ICH}[6]$.

\section{Ethical considerations}

After the patient was treated in the ICU for a few days but the patient did not show improvement even the condition decreased progressively, then DCP took the initiative to limit support for therapy (withholding life support). In accordance with standard operating procedures at the ICU, to take action withholding life support, the DCP consults with the medical committee and ethical committee. In making ethical and medicolegal decisions in this case, the medical committee and ethical committee apply the basic ethical principles/rules of beneficence and nonmaleficence [11], [12].
Determination of withholding life support and withdrawing life support in some places is still controversial, but using the principle of beneficence and non-maleficence, this dilemma situation can be resolved. Benefits, as the original word said, benefits relate to always providing the best benefits for patients [7], [11], [12]. The condition of this patient after being treated for several days did not show the expected results with the treatment itself being in vain, so the administration of therapy in patients did not meet the principle of benefit.

Likewise, if therapy continues with the consequences of not providing benefits to patients, then this can also be a disadvantage for patients and their families in terms of time, financial, and comfort, then this also contradicts the principle of non-maleficence [7]. Non-maleficence is intended as far as possible the doctor prevents harm to the patient (prevents loss) [11], [12].

In making decisions for actions withholding life support, the doctors must give attention to the situation and condition of the patient and his family including the time and place that are comfortable to convey this to the patient's family. The doctor must respect the dignity of the patient in this case the patient's right of autonomy [7], by providing relevant information about the patient's condition [13]. The doctor must ensure the patient's family understands the terminal condition of the patient's illness [14]. The doctor must also understand well how the criteria for decision-making. Withholding life support and withdrawing life support are when medical indications have changed from ordinary to extraordinary [15]. Determination of which medical indications are ordinary or extraordinary becomes very important as a basis for doctors in carrying out professional actions in accordance with ethical and medicolegal rules [16].

An ordinary medical procedure is all medical or surgical procedures or the administration of drugs that beneficently provide hope or benefits for patients, with the criteria of "improving the situation" reasonable, obtained or carried out without excessive costs, extreme pain, painstakingly, or other inconvenience. The criteria for ordinary medical action are useful, rationally available, statistically proven, and not financially burdensome. Meanwhile, if the medical procedure is carried out with excessive financial costs, pain, or discomfort, or if it is done and does not offer hope of improving the situation, then it becomes extraordinary, thus the medical procedure is not mandatory [16], [17]. In this case, the neurosurgery operation and neuroanesthesia in patients with extensive $\mathrm{ICH}$ based on neurosurgical analysis do not provide hope for improvement in patients, the medical treatment is extraordinary.

This principle is derived from the opinion of a doctor from Spain, Domingo Bañez (1528-1604). The question Bañez asked at that time: "Is someone obliged to amputate his hand when someone's hand is affected by a disease that will spread and endanger his life?" [16]. 
This question at that time was important because at that time the anesthesia was not there yet. In the absence of anesthesia, this becomes extraordinary because amputation of the hand causes unbearable pain, so amputation is not mandatory. In contrast to the present condition, because there is an anesthetic procedure, hand amputation becomes ordinary [16], [18].

Ethical considerations for decision-making withholding life support must be done carefully, whether the procedure includes treatment (cure) or attention (care). If the medical procedure is a "cure" and is considered to have been in vain (futile treatment), then it can be limited/stopped, but if it is still considered "care," then the cessation of the procedure is unethical [11]. In this case, performing a neurosurgery operation with anesthetic procedure is a "cure," but it is predicted that the results will be in vain, so the doctor took the initiative to do "care" with conservative care. Limitation of therapy in extraordinary conditions does not mean that the patient does not receive treatment, ordinary care is still given such as basic living needs such as food and drinks (through parenteral/infusion and nasogastric tube), air also social nature such as affection, attention, and spirituality in palliative care which aims to improve the quality of life in its terminal period [12], [16], [17], [18].

Determination of the boundary between ordinary and extraordinary is very necessary, because if the DCP has hands off because cannot do anything else for patients who have been very severe (terminal state) or therapy has been in vain (futile) and as a form of awareness that medical science is limited then there is a point where the doctor has to say "enough." Cessation of what is extraordinary is not the same as euthanasia, because it is different from the "mens rea" or despair but rather as a form of submission and acceptance of human nature when faced with death which is indeed inevitable. For the DCP, the boundary between ordinary and extraordinary is necessary so that there is no feel guilty when limiting or stopping futile and aggressive treatment for patients [12], [15], [16], [17], [18].

\section{Medicolegal considerations}

The statutory provisions in Indonesia have governed the determination of withdrawal or withholding measures for therapeutic support, which are listed in the Regulation of the Minister of Health of the Republic of Indonesia Number 37 of 2014 Chapter 3 Articles 14 and 15 concerning the termination or limitation of life assistance therapy. In the regulation stated that the termination or limitation of life assistance therapy can be done on patients who are in an incurable condition due to their illness (terminal state) and the medical action has been in vain (futile treatment) [19].

The hospital director determines policies regarding the patient's condition criteria that can be carried out withholding life support and withdrawing life support. The DCP and the team of doctors who deal with patients consult with the team of doctors appointed by the medical committee or the ethics and legal committee of the hospital [19]. The action plan withholding life support and withdrawing life support must be informed after the DCP consults with the medical committee/ethical committee and obtains approval from the patient's immediate family or who represents the patient, in accordance with the Regulation of the Minister of Health of the Republic of Indonesia number 290 of 2008 Chapter 4 article 16 regarding approval of medical measures in special situations [20].

Life-support therapy that can be stopped or postponed is only therapeutic and/or extraordinary treatment, namely, intensive care, mechanical ventilation, pulmonary resuscitation, tracheal intubation, dysrhythmic control, vasoactive drugs, artificial organs, nutrition parenteral, transplantation, blood transfusion, invasive monitoring, and administration of antibiotics and other measures stipulated in medical service standards. Life support therapy that cannot be stopped or postponed includes oxygen, enteral nutrition, and crystalloid fluids [20]. In this case, there are two conditions that support the decision to take withholding life support: The patient is in terminal state disease with GCS 3 awareness, post-CS on indications of eclampsia and HELLP syndrome which have been very severe with worsening patient's condition after being treated optimally in the ICU, as well as extensive ICH conditions with no indication of surgery because the results are predicted to be futile.

\section{Conclusion}

The ethical principles of decision-making for withholding and withdrawing life support therapy in critical care problems are beneficence and nonmaleficence based on the consideration that the therapy is ordinary and extraordinary. If ordinary is continued, but if extraordinary, therapy can be discontinued. The medicolegal principle in these patients lies in the patient's condition which cannot be cured medically (terminal state) and medical action is useless (futile). These two principles form the basis for making professionally accountable medical decisions.

\section{References}

1. Triana E, Syahredi SA. Antepartum eclampsia in G5P4A0H3 gravid preterm 33-34 weeks + HELLP syndrome + Acute kidney injury+ IUFD. J Kes Andalas. 2019;8:79-83.

2. Lusiana N. Factors related to the incidence of preeclampsia in pregnant women in the Camar room II Arifin Achmad Hospital, 
Riau Province in 2014. J Kes Kom. 2015;3(1):29-33.

3. Ahishali E. Liver diseases associated with pregnancy. Marmara Med J. 2012;25:1-4.

4. Cippola MJ, Kraig RP. Seizures in women with preeclampsia: Mechanisms and management. Fetal Matern Med Rev. 2011;22(2):91-108. https://doi.org/10.1017/ S0965539511000040

PMid:21709815

5. Minire A, Mirton M, Imri V, Lauren M, Aferdita M. Maternal complications of preeclampsia. Med Arch. 2013;67(5):339-41.

6. Septica RI, Uyun Y, Suryono B. Cerebrovascular pathophysiology and anesthesia implications in preeclampsia/eclampsia. J Neuroanes Indon. 2015;4(2):134-48.

7. Regnier J, Pierssens AR, Boulain T, Carpentier F, Le Borgne P, Delnista $\mathrm{D}$, et al. Withholding and withdrawing life-support in adults in emergency care: Joint position paper from the French intensive care society and French society of emergency medicine. Ann Intensive Care. 2019;9(105):1-7. https://doi. org/10.1186/s13613-019-0579-7

PMid:31549266

8. Salloch S. Same same but different: Why we should care about the distinction between professionalism and ethics. BMC Med Eth. 2016;17(44):1-6.

9. Muhani B, Besral B. Severe pre-eclampsia and maternal death. J Kes Mas Nas. 2015;10(2):80-6.

10. Hammer ES, Cippola MJ. Cerebrovascular dysfunction in preeclamptic pregnancies. Curr Hypertens Rep. 2015;17(8):1-13. https://doi.org/10.1007/s11906-015-0575-8

PMid:26126779

11. Varkey B. Principles of clinical ethics and their application to practice. Med Princ Pract 2021;30(1):17-28. https://doi. org/10.1159/000509119 PMid:32498071

12. Welle JV, ten Have HA. The ethics of forgoing life-sustaining treatment: Theoretical considerations and clinical decision making. Multidiscip Resp Med. 2014;9(14):1-8. https://doi. org/10.1186/2049-6958-9-14

PMid:24618004

13. Phua J, Joynt GM, Nishimura M, Deng Y, Myatra SN, Chan YH, et al. Withholding and withdrawal of life-sustaining treatments in intensive care units in Asia. JAMA Intern Med. 2015;175(3):363-71. https://doi.org/10.1001/jamainternmed.2014.7386 PMid:25581712

14. Willmott L, White B, Smith MK, Wilkinson DJ. Withholding and withdrawing life-sustaining treatment in a patient's best interests: Australian judicial deliberations. Med J Aust. 2014;201(9):545-7. https://doi.org/10.5694/mja13.10874 PMid:25358584

15. Malik MM. Islamic perceptions of medication with special reference to ordinary and extraordinary means of medical treatment. Bangladesh J Bioethics. 2013;4(2):22-33.

16. Suryadi T. Bioethical and medicolegal aspects withholding and withdrawing life support therapy in critical care. J Ked Syiah Kuala. 2017;17(1):60-4.

17. McTavish RJ. Justice and health care: When "ordinary" is extraordinary. Linacre Q. 2016;83(1):26-34. https://doi.org/10.1 080/00243639.2015.1123891

PMid:27833180

18. Kearns AJ, Gordijn B. Withholding and withdrawing life-saving treatment: Ordinary/extraordinary means, autonomy and futility. Anal I Egzystencja. 2018;42:5-33.

19. Republic of Indonesia. Regulation of the Minister of Health of the Republic of Indonesia Number 37 of 2014, Concerning the Withholding and Withdrawing Life Support Therapy. Indonesia: Republic of Indonesia; 2014.

20. Republic of Indonesia. Regulation of the Minister of Health of the Republic of Indonesia Number 290 of 2008, Concerning Approval and Rejection of Medical Treatment. Indonesia: Republic of Indonesia; 2008. 